Revista Brasil. Bot., V.32, n.4, p.737-748, out.-dez. 2009

\title{
Schizaeales no Parque Estadual do Itacolomi, Minas Gerais, Brasil
}

\author{
JANE EYRE CASARINO ${ }^{1}$, CLAUDINE MASSI MYNSSEN ${ }^{2,4} \mathrm{e}$ \\ MARIA CRISTINA TEIXEIRA BRAGA MESSIAS ${ }^{3}$
}

(recebido: 29 de novembro de 2007; aceito: 2 de setembro de 2009)

\begin{abstract}
Schizaeales from Itacolomi State Park, Minas Gerais, Brazil) This work presents the taxonomic study of Schizaeales from Itacolomi State Park, located in Ouro Preto and Mariana Municipalities, Minas Gerais State, Brazil. The vegetation of the Park is mostly formed by campos rupestres and semideciduous forests. The Schizaeales is found primarily in tropics and southern temperate zones, consisting of three families: Schizaeaceae, Anemiaceae and Lygodiaceae. Fourteen taxons were found: Anemia (11 species, including three varieties), Lygodium (one species), Schizaea (one species). Six taxons were recognized as endemics to Brazil. Identification keys, descriptions, illustrations and comments are presented.
\end{abstract}

Key words - Anemiaceae, ferns, Lygodiaceae, Ouro Preto, Schizaeaceae

RESUMO - (Schizaeales no Parque Estadual do Itacolomi, Minas Gerais, Brasil) Esse trabalho consiste no estudo taxonômico das Schizaeales no Parque Estadual do Itacolomi, localizado nos municípios de Ouro Preto e Mariana, Estado de Minas Gerais, Brasil. O Parque é constituído principalmente por campos rupestres e florestas estacionais semideciduais. A ordem Schizaeales ocorre essencialmente em ambientes tropicais e temperado meridional, sendo constituída por três famílias: Schizaeaceae, Anemiaceae e Lygodiaceae. Foram encontrados 14 táxons, distribuídos em três gêneros: Anemia (11 espécies, com reconhecimento de três variedades), Lygodium (uma espécie), Schizaea (uma espécie). Do total de táxons estudados, seis são endêmicos do Brasil. São apresentadas chaves de identificação, descrições, ilustrações e comentários.

Palavras-chave - Anemiaceae, Lygodiaceae, Pteridófitas, Ouro Preto, Schizaeaceae

\section{Introdução}

A classificação mais recente das Monilófitas atuais (Smith et al. 2006) restabelece a Ordem Schizaeales Reed, com três famílias distintas: Anemiaceae (Anemia e Mohria), Lygodiaceae (Lygodium) e Schizaeaceae (Actinostachys e Schizaea). O tratamento taxonômico desses grupos tem diferido entre os autores. Reed (1947) propôs que os gêneros Anemia, Mohria, Lygodium e Schizaea fossem tratados em famílias distintas por serem morfologicamente diversos e especializados. Muitos autores trataram estes gêneros em uma única família, Schizaeaceae, pelo fato de compartilharem características importantes tais como ânulo apical do esporângio (Tryon \& Tryon 1982; Kramer 1990; Smith 1995). Os estudos moleculares apresentados por Hasebe et al. (1994) mostraram claramente que constituem um grupo monofilético e a grande diversidade morfológica na família poderia ser explicada pela sua longa história evolutiva.

1. Universidade Federal de Ouro Preto, Pós-Graduação em Biomas Tropicais, Morro do Cruzeiro, 35400-000 Ouro Preto, MG, Brasil.

2. Instituto de Pesquisa Jardim Botânico do Rio de Janeiro, Rua Pacheco Leão 915, 22460-030 Rio de Janeiro, RJ, Brasil.

3. Universidade Federal de Ouro Preto, Departamento de Biodiversidade Evolução e Meio Ambiente, Morro do Cruzeiro, 35400-000 Ouro Preto, MG, Brasil.

4. Autor para correspondência: cmynssen@jbrj.gov.br
O objetivo deste estudo foi inventariar, descrever e ilustrar as espécies de Schizaeales ocorrentes no Parque Estadual do Itacolomi, o qual faz parte do centro de diversidade de espécies desse grupo. Além disso, fornecer uma chave analítica para identificação dos táxons ocorrentes na área.

\section{Material e métodos}

O Parque Estadual do Itacolomi (PEI) é uma Unidade de Conservação criada pela Lei no 4495 de 19 de junho de 1967. Está situado nos municípios de Ouro Preto e Mariana, com uma área estimada em 7.000 ha, sendo o ponto mais elevado o Pico do Itacolomi com $1.772 \mathrm{~m}$. Abrange a maior parte da Serra do Itacolomi, compondo o limite sul da Cadeia do Espinhaço ou Serra Geral (Dutra et al. 2005). Sua vegetação é constituída por campos rupestres, permeados por manchas de florestas estacionais semi-deciduais. A região do Parque ocupa a zona de transição entre os domínios da Mata Atlântica e do Cerrado (Veloso et al. 1991). O clima é do tipo Cwb (Köppen), temperado úmido com inverno seco e verão quente e chuvoso. As temperaturas anuais oscilam entre $17^{\circ} \mathrm{C}$ a $23^{\circ} \mathrm{C}$ (Feam 1995 apud Werneck et al. 1999).

Foram realizadas excursões quinzenais durante um ano, abrangendo principalmente as Trilhas do Calais, do Pico, do Forno, Estradas da Fazenda do Manso e da Bacia do Custódio, localizadas no município de Ouro Preto, e Estrada do Cibrão no município de Mariana. Os espécimes foram herborizados e incorporados aos acervos dos Herbários Professor José 
Badini da Universidade Federal de Ouro Preto (OUPR) e do Jardim Botânico do Rio de Janeiro (RB).

Para identificação e análise da distribuição geográfica dos táxons utilizou-se principalmente: Kramer (1990), Maguire et al. (1969), Mickel (1962, 1982), Mickel \& Beitel (1988), Sehnem (1974) e Tryon \& Tryon (1982). Foram examinados os espécimes depositados nos Herbários OUPR, RB e da Universidade Federal de Minas Gerais (BHCB). A citação das abreviaturas dos autores das espécies foi feita segundo Pichi-Sermolli (1996).

\section{Resultados e discussão}

\section{SCHIZAEALES}

Plantas terrestres, rupícolas, raramente epífitas; caule reptante ou ereto; frondes eretas, prostradas ou escandentes; lâminas inteiras, dicotômicas ou segmentadas; nervuras livres ou anastomosadas; esporangióforos em pinas basais modificadas ou na margem modificada da lâmina ou do segmento.

As famílias Lygodiaceae, Anemiaceae e Schizaeaceae agrupadas nesta ordem são caracterizadas principalmente por apresentarem diferenciação das lâminas férteis e estéreis, a ausência de soro bem definido e o esporângio com ânulo transversal subapical (Smith et al. 2008).

Schizaeales ocorre essencialmente em ambientes tropicais e temperado meridional. Na área de estudo foram encontrados 14 táxons, distribuídos em três gêneros: Anemia (11 espécies, incluindo três variedades), Lygodium (uma espécie), Schizaea (uma espécie).

Chave para identificação das famílias de Schizaeales do Parque Estadual do Itacolomi

1. Raque volúvel, escandente Lygodiaceae (Lygodium volubile)

1. Raque ereta, não escandente

2. Esporangióforos localizados na margem da lâmina, esporos monoletes .... Schizaeaceae (Schizaea elegans)

2. Esporangióforos localizados em duas pinas basais modificadas, esporos triletes

Anemiaceae

\section{ANEMIACEAE Link}

Plantas com caule reptante ou ereto, com tricomas; frondes eretas ou prostradas; pecíolos com tricomas ou glabros; lâminas lobadas, pinadas, ou bipinadas, pinas inteiras ou pinatífidas, nervuras livres, furcadas ou anastomosadas; esporangióforos localizados em duas pinas ou segmentos basais modificados, esporos tetraédrico-globosos, triletes.
De acordo com Mickel (1982), cerca de 120 espécies (Mickel \& Smith 2004) de Anemia são amplamente distribuídas na América Tropical, 10 na África e uma no sul da Índia. Ainda segundo este autor, no Brasil existe a mais alta concentração de espécies (acima de 70), a maior parte nos planaltos de Goiás e Minas Gerais e nas florestas das montanhas costeiras do Espírito Santo a Santa Catarina.

Chave para identificação das espécies e variedades de Anemia do Parque Estadual do Itacolomi

1. Nervuras anastomosadas

2. Pinas lanceoladas, ápice agudo ou acuminado, nervuras anastomosadas até a margem 8. A. phyllitidis

2. Pinas ovadas, ápice obtuso, 1-2 anastomoses próximas à costa ou na região mediana da pina 5. A. nervosa

1. Nervuras livres e furcadas

3. Frondes prostradas, dispostas em roseta 1. A. elegans

3. Frondes eretas, sem esta disposição

4. Lâmina pinada

5. Pina apical flabeliforme inteira, basais ovadas a elípticas, eqüilaterais 6. A. oblongifolia

5. Pina apical oblonga, oblongo-lobada ou oblongo-flabeliforme, basais inequilaterais

6. Pinas 6-12 pares, apical oblongo-lobada ou oblongo-flabeliforme 7. A. pallida

6. Pinas 25-31 pares, apical oblonga 4. A. mandioccana

4. Lâmina pinado-pinatífida, bipinada ou bipinado-pinatífida 
7. Lâmina pinado-pinatífida

8. Lâmina oblonga a oblongo-lanceolada, esporangióforos delgados

(0,5-0,9 cm larg.)

11. A. villosa

8. Lâmina deltóide a oblongo-ovada, esporangióforos robustos

(1,3-1,5 cm larg.)

4. A. imbricata

7. Lâmina bipinada ou bipinado-pinatífida

9. Caule com tricomas castanhos a ferrugíneos (A. ferruginea)

10. Pínulas pinatífidas no 1/3 mediano e proximal da lâmina, ápice

agudo a acuminado

2.1. A. ferruginea var. ahenobarba

10. Pínulas pinatífidas no $1 / 3$ proximal da lâmina, ápice obtuso 2.2. A. ferruginea var. ferruginea

9. Caule com tricomas castanho-alaranjados

11. Pinas medianas pinatífidas, basais bipinatífidas, ovadas a oblongo-ovadas

9. A. raddiana

11. Pinas medianas e basais bipinatífidas, lanceoladas ou oblongo-lanceoladas

10. A. tomentosa var. anthriscifolia

1. Anemia elegans (Gardner) C. Presl, Suppl. Tent. Pterid. 81. 1845. $\equiv$ Trochopteris elegans Gardner, London Jour. Bot. 1:74. t.4. 1842.

Figuras 1A, B

Caule ereto, ca. 2-3 mm diâm., com tricomas septados ca. 2-5 mm compr., alaranjados a castanho claros. Frondes prostradas, sésseis ou curtamente pecioluladas, dispostas em roseta; pecíolo 2-6 mm compr., castanho, com tricomas semelhantes aos do caule; lâminas flabelado-lobadas, membranáceas, 5-20 × 6-16 mm, tricomas semelhantes aos do pecíolo nas duas faces; nervuras livres e furcadas. Esporangióforos sésseis, localizados na margem de dois segmentos basais modificados.

Embora esta espécie tenha sido coletada recentemente em Campo Rupestre na Serra do Capanema, localidade próxima da área de estudo, não há registros recentes no PEI. Tem distribuição geográfica registrada para América Central e América do Sul. No Brasil ocorre nos Estados de Goiás, Mato Grosso e Minas Gerais.

Material examinado: BRASIL, Minas Gerais: Ouro Preto, Itacolomi, 1903, L. Damazio s.n. (RB 36906).

2. Anemia ferruginea Humb. \& Bonpl. ex Kunth, Nov. Gen. Sp. 1:32. 1815.

2.1. Anemia ferruginea Humb. \& Bonpl. ex Kunth var. ahenobarba (Christ) Mickel, Iowa State J. Sci. 36:430. 1962. $\equiv$ Anemia ahenobarba Christ, Pl. Nov. Mineiras 2:37. 1900.

Figura 1C

Caulereptante, 5-7 mm diâm., com tricomas septados 1-4 mm compr., castanho escuros. Frondes eretas, cespitosas, pecíolos da fronde estéril com 4-8 cm compr., pecíolos da fronde fértil com 10-18 cm compr. (ca. 2/3 do compr. da lâmina), castanho escuros na porção proximal, castanho claros ou amarelados na porção distal, sulcados adaxialmente, com tricomas 2-7 mm compr., pardos a castanho claros; lâmina bipinado-pinatífida, deltóide a oblongo-deltóide, coriácea, 6-10 × 3-6 cm, raque com tricomas semelhantes aos do pecíolo; pinas 8-13 pares, 1,5-3,5 × 0,5-1 cm, medianas e apicais lanceoladas ou oblongo-lanceoladas, basais ovadas; pínulas pinatífidas no 1/3 mediano e proximal da lâmina, ovadas a oblongas, ápice agudo a acuminado, com tricomas semelhantes aos da raque nas duas faces; nervuras livres e furcadas. Esporangióforos eretos, delgados 0,5-0,7 cm larg., dispostos em duas pinas basais modificadas, excedendo em 1-2 cm a lâmina fértil, peciólulo curto $c a$. 1/2 do compr. do esporangióforo.

Foram verificados que os indivíduos que ocorrem em campo quartzítico possuem uma grande variação quanto ao tamanho das frondes. A. ferruginea var. ahenobarba pode ser distinguida da variedade típica pela maior dissecção da lâmina e pelas pínulas com ápice mais agudo ou acuminado (Mickel 1962). Porém, na área de estudo, foi verificada a ocorrência de indivíduos com características intermediárias. Está restrita ao Brasil, sendo encontrada nos Estados de Mato Grosso, Goiás, Bahia, Minas Gerais.

Material examinado: BRASIL. MinAs GeRAIS: Ouro Preto, Parque Estadual do Itacolomi, Trilha do Calais, 23-III-2004, Casarino 12 (OUPR); base da Serra do Itacolomi, 1936, Badini s.n. (RB 31003).

2.2. Anemia ferruginea Humb. \& Bonpl. ex Kunth var. ferruginea, Nov. Gen. Sp. 1:32. 1815.

Figura 1D 


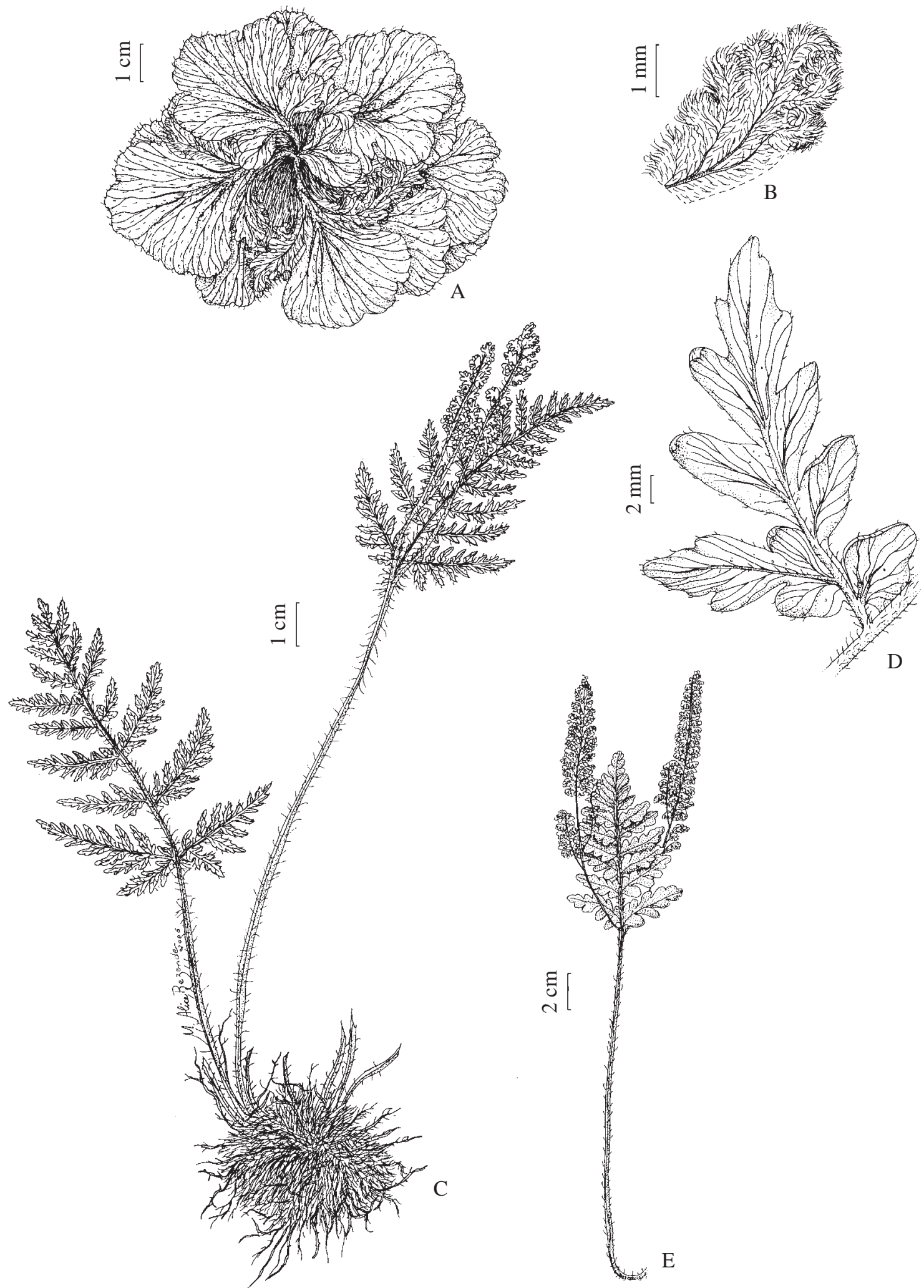

Figura 1. A-B. Anemia elegans. A. Hábito. B. Segmento fértil (RB 36906). C. Anemia ferruginea var. ahenobarba, hábito (Casarino 12). D. Anemia ferruginea var. ferruginea, pina basal (Casarino 18). E. Anemia imbricata, fronde (Casarino 8).

Figure 1. A-B. Anemia elegans. A. Habit. B. Fertile segment (RB 36906). C. Anemia ferruginea var. ahenobarba, habit (Casarino 12). D. Anemia ferruginea var. ferruginea, basal pinna (Casarino 18). E. Anemia imbricata, frond (Casarino 8). 
Caule reptante, 4-15 mm diâm., com tricomas septados 5-10 mm compr., castanhos a ferrugíneos. Frondes eretas, cespitosas; pecíolos da fronde estéril com 6-17 cm compr., pecíolos da fronde fértil com 13-35 cm compr. (ca. 2/3 do compr. da lâmina), castanho escuros, ou com porção distal castanho clara, sulcados adaxialmente, com tricomas 1-5 mm compr., amarelados a ferrugíneos; lâmina bipinado-pinatífida, deltóide a oblongo-deltóide, cartácea, 3,5-13 × 2,5-6 cm, raque com tricomas semelhantes aos do pecíolo, ligeiramente mais claros; pinas apicais e medianas lanceoladas ou oblongolanceoladas, basais ovadas a oblongo-ovadas, 6-10 pares, 2-4 × 0,5-1 cm; pínulas pinatífidas no 1/3 proximal da lâmina, ovadas a oblongas, ápice obtuso, com tricomas semelhantes aos da raque nas duas faces; nervuras livres e furcadas. Esporangióforos eretos, delgados, 0,7-1 cm larg., dispostos em duas pinas basais modificadas, excedendo em 2-4 cm a lâmina fértil, peciólulo curto $1 / 2$ ou $1 / 3$ do compr. do esporangióforo.

Ocorre sobre rochas em locais sombreados, entre vegetação herbácea. Esta variedade tem ampla distribuição na América Tropical ocorrendo da América Central a América do Sul. No Brasil é encontrada desde o Estado do Amazonas ao Paraná.

Material examinado: BRASIL. MinAs Gerais: Ouro Preto, Parque Estadual do Itacolomi, Trilha do Calais, 23-III-2004, Casarino 18 (OUPR); Mariana, Parque Estadual do Itacolomi, Estrada do Cibrão, 9-VI-2005, Jascone 390 (RB).

3. Anemia imbricata Sturm, Fl. Bras. 1(2):205. 1958. Figura 1E

Caule reptante, 8-12 mm diâm., com tricomas septados 2-7 mm compr., castanho alaranjados ou avermelhados. Frondes eretas, cespitosas; pecíolos da fronde estéril com 5-15 cm compr., pecíolos da fronde fértil com 13-25 cm compr. (ca. 2/3 do compr. da lâmina), castanho nigrescentes na porção proximal, castanho escuros na porção distal, sulcados adaxialmente, com tricomas 2-7 mm compr., castanho claros; lâmina pinado-pinatífida, deltóide a oblongo-ovada, cartácea, $5-12 \times 2,5-6 \mathrm{~cm}$, raque com tricomas semelhantes aos do pecíolo; pinas apicais, medianas e basais lanceoladas ou oblongo-lanceoladas, 6-13 pares, 2-5 × 0,5-1,2 cm, ápice obtuso, com tricomas semelhantes aos da raque nas duas faces; nervuras livres e furcadas. Esporangióforos eretos, robustos, 1,3-1,5 cm larg., ramificações longas (2,5-3,5 cm), dispostos em duas pinas basais modificadas, excedem 1-4 cm a lâmina fértil ou não, peciólulo curto ca. $1 / 2$ ou $1 / 3$ do compr. do esporangióforo.
Esta espécie forma densas populações em locais sombreados sobre rochas, barrancos úmidos ou em campos abertos. Geralmente é confundida com Anemia villosa Willd., mas esta pode ser diferenciada por possuir esporangióforos delgados (0,5-0,9 cm), lâmina oblonga a oblongo-lanceolada. Existem indivíduos com grande variação morfológica na lâmina o que torna, às vezes, a identificação difícil. Os espécimes de maior porte de $A$. imbricata podem ser confundidos com $A$. raddiana por possuírem a lâmina deltóide ou ovado-deltóide, porém essa possui lâmina bipinado- pinatífida e esporangióforos são mais delgados. A. imbricata é considerada endêmica de Minas Gerais (Mickel 1962).

Material examinado: BRASIL. MinAs Gerais: Ouro Preto, Parque Estadual do Itacolomi, Trilha do Calais, 23-III-2004, Casarino 7, 8, 10, 20 (OUPR); 23-III-2004; base da Serra do Itacolomi, 1936, Badini s.n. (RB 30399).

4. Anemia mandioccana Raddi, Opusc. Sci. Bol. 3:282. 1819.

Caule ereto, 7 mm diâm., com tricomas septados 2-7 mm compr., castanhos alaranjados a avermelhados. Frondes eretas, fasciculadas; pecíolos com $12-20 \mathrm{~cm}$ compr. (ca. 1/3 do compr. da lâmina), castanhos, sulcados adaxialmente, com tricomas semelhantes aos do caule; lâmina pinada, oblonga a oblongo-lanceolada, membranácea, $18-25 \times 3,5-5 \mathrm{~cm}$, raque com tricomas semelhantes aos do pecíolo; pinas 25-31 pares, 2-3 × 0,7$1 \mathrm{~cm}$, apical oblonga, medianas e basais subdimidiadas, inequilateral, margem inteira a crenada, com tricomas semelhantes aos da raque, esparsos nas duas faces; nervuras livres e furcadas. Esporangióforos eretos, 5-7 cm compr., delgados, 0,3-0,5 cm larg., dispostos em duas pinas basais modificadas, não excedendo a lâmina fértil, peciólulo longo, ca. do comprimento do esporangióforo.

Esta espécie tem distribuição geográfica restrita ao Brasil, ocorrendo nos Estados da Bahia, Minas Gerais, Rio de Janeiro e São Paulo. Embora Anemia mandioccana seja muito freqüente nas florestas úmidas da Costa Atlântica brasileira, não há registros recentes para as regiões úmidas do Parque Estadual do Itacolomi. Geralmente é confundida com A. blechnoides Sm., que ocorre nas montanhas úmidas da Costa Atlântica, freqüentemente identificada nos herbários como $A$. radicans Raddi. Esta espécie pode ser distinguida pela pina apical oblonga ou oblongo-flabeliforme, com tricomas castanho-alaranjados a avermelhados no caule, pecíolo e raque. A. blechnoides possui caule, pecíolo 
e raque com tricomas castanhos e o ápice da raque é radicante.

Material examinado: BRASIL. Minas Gerais: Ouro Preto, Parque Estadual do Itacolomi, Trilha do Manso, 24-VI-1902, Schwacke s.n. (RB 347050).

5. Anemia nervosa Pohl, Fl. Bras. 1(2):193. 1859. Figura 2E

Caule ereto, 5-7 mm diâm., com tricomas septados 2-5 mm compr., castanho ferrugíneos. Frondes eretas, fasciculadas; pecíolos da fronde estéril com 3-10 cm compr., pecíolos da fronde fértil com 8-22 cm compr. (ca. 2/3 do compr. da lâmina), verdes quando vivos ou castanho claros quando secos, sulcados adaxialmente, com tricomas semelhantes aos do caule; lâmina pinado, ovada a oblongo-ovada, cartácea, 5,5-14 × 4-8,5 cm, raque com tricomas semelhantes aos do pecíolo; pinas 4-6 pares, 2,5-4,5 × 1,5-2 cm, apicais flabeladas ou deltóide lobada, medianas e basais ovadas, com tricomas semelhantes aos da raque nas duas faces; nervuras 1-2 anastomoses próximas à costa ou na região mediana da pina, depois furcadas. Esporangióforos eretos, dispostos em duas pinas basais modificadas, excedendo em até $5 \mathrm{~cm}$ a lâmina fértil, peciólulo longo $\mathrm{ca}$. do mesmo tamanho ou ligeiramente maior que o esporangióforo.

Esta espécie foi encontrada em barrancos úmidos e sombreados, próxima a indivíduos de A. phyllitidis (L.) Sw. Assemelha-se a A. phyllitidis, mas esta pode ser diferenciada dessa pelos tricomas alaranjados ou castanho claros da lâmina e pelas nervuras anastomosadas até a margem. É considerada uma espécie endêmica do Brasil, ocorrendo nos Estados de Minas Gerais e Goiás.

Material examinado: BRASIL. MinAs Gerais: Mariana, Parque Estadual do Itacolomi, Estrada do Cibrão, 9-VI-2005, Casarino 48 (OUPR); Ouro Preto, 1887, Damazio s.n. (RB 105048); Ouro Preto, 1904, Damazio s.n. (RB 36880); s.d., Schwacke 13401 (RB).

6. Anemia oblongifolia (Cav.) Sw., Syn. Fil. 156. 1806. 三Osmunda oblongifolia Cav., Icon. 6:69, t.592, f.2. 1801.

Figuras 2A, B, C, D

Caulereptante, 5-8 mm diâm., com tricomas septados 1-5 mm compr., castanho escuros. Frondes prostadas ou eretas; pecíolos da fronde estéril com 2-7 cm compr.; pecíolos da fronde fértil com 3-13 cm compr. (ca. 2/3 do compr. da lâmina), amarelados a castanho claros, sulcados adaxialmente, com tricomas semelhantes aos do caule; lâmina pinada, oblonga, cartácea a coriácea, $2-8 \times 1-2,5 \mathrm{~cm}$, raque com tricomas semelhantes aos do pecíolo; pinas 3-5 pares, 0,8-1,5 × 0,6-0,8 cm, apical flabeliforme inteira, medianas e basais ovados a elípticos, eqüilaterais, ápice obtuso a arredondado, com tricomas semelhantes aos da raque nas duas faces; nervuras livres e furcadas. Esporangióforos eretos, dispostos em duas pinas basais modificadas, excedendo em 3-7 cm a lâmina fértil, peciólulo longo, $c a$. 2 vezes o comprimento do esporangióforo.

Os indivíduos ocorrem sobre rochas ou em grotas, em locais úmidos e sombreados, sendo poucos heliófilos. Os espécimes examinados possuem uma grande variação morfológica quanto à consistência da lâmina (cartácea a coriácea), quanto à densidade de tricomas sobre a lâmina, além de apresentarem o número e tamanho das pinas muito variáveis. Ocorre do México a América do Sul e no Brasil está distribuída nas regiões norte, nordeste e centro-oeste, chegando ao Estado de Minas Gerais.

Material examinado: BRASIL. MinAs Gerais: Mariana, Parque Estadual do Itacolomi, Estrada do Cibrão, 24-III-2004, Casarino 19, 27, 28 (OUPR); 9-VI-2005, Jascone 389 (RB); Ouro Preto, Parque Estadual do Itacolomi, Trilha do Calais, 6-VIII-1998, Labiak \& Roschel s.n. (OUPR 16973); 23-III-2004, Casarino 16, 17 (OUPR); Itacolomi, 1936, Badini s.n. (RB 30396); s.d. Damazio s.n. (RB 36918).

7. Anemia pallida Gardner, Field. \& Gardn. Sert. pl. ad t.70. 1844.

Figura 2F

Caule reptante, 8-11 mm diâm., com tricomas multiseptados 2-7 mm compr., castanho claros a amarelados. Frondes eretas, cespitosas; pecíolos da fronde estéril com 3-12 cm compr., pecíolos da fronde fértil com 4-20 cm compr. (ca. 2 a 4 vezes o compr. da lâmina), esverdeados a castanho claros, sulcados adaxialmente, com tricomas esparsos semelhantes aos do caule; lâmina pinada, oblonga a oblongo-ovada, cartácea, 4-11 × 3,0-5,5 cm, raque com tricomas semelhantes aos do pecíolo; pinas 6-12 pares, 1-1,5 × 0,3-0,7 cm, apical oblongo-lobada ou oblongo-flabeliforme, medianas e basais oblongas, subdimidiadas, inequilateral, margem inteira ou crenada a inciso-crenada, com tricomas semelhantes aos da raque nas duas faces. Nervuras livres e furcadas. Esporangióforos eretos, dispostos em duas pinas basais modificadas, excedendo em $c a .2 \mathrm{~cm}$ a lâmina fértil, peciólulo longo $c a$. 2 vezes o tamanho do esporangióforo.

Esta espécie ocorre em barrancos úmidos e sombreados às margens de trilhas e estradas. Segundo Mickel (dados não publicados) é endêmica do Brasil, 

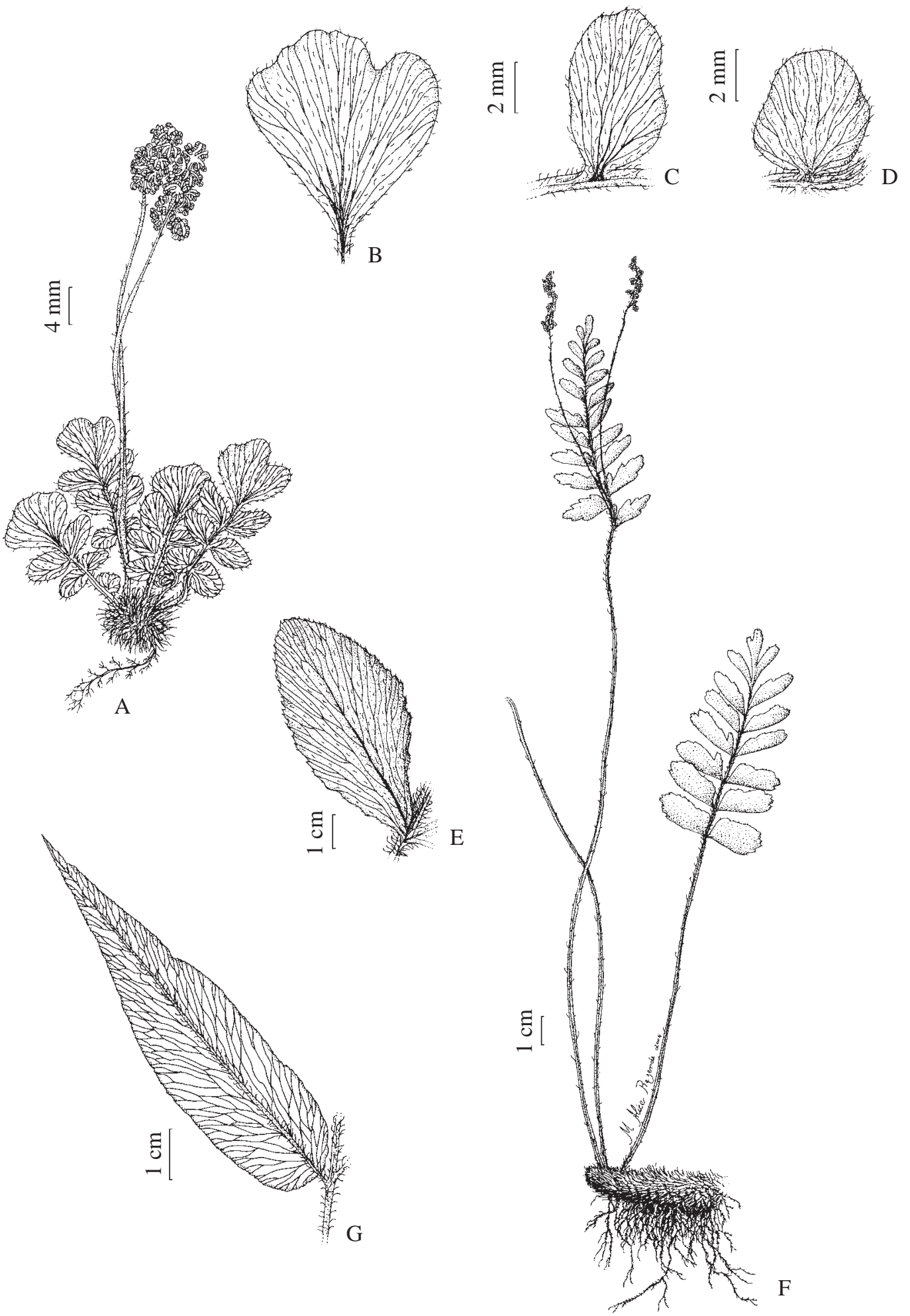

Figura 2. A-D. Anemia oblongifolia. A. Hábito. B. Pina apical. C. Pina mediana. D. Pina basal (OUPR 16973). E. Anemia nervosa, pina mediana (Schwacke 13401). F. Anemia pallida, hábito (Jascone 370). G. Anemia phyllitidis, pina mediana (OUPR 16968).

Figure 2. A-D. Anemia oblongifolia. A. Habit. B. Apical pinna. C. Medial pinna. D. Basal pinna (OUPR 16973). E. Anemia nervosa, medial pinna (Schwacke 13401). F. Anemia pallida, habit (Jascone 370). G. Anemia phyllitidis, medial pinna (OUPR 16968). 
ocorrendo em Goiás e Minas Gerais. Assemelha-se a Anemia pastinacaria Moritz ex Prantl, porém esta espécie possui as pínulas mais largas $(0,7-1,2 \mathrm{~cm})$.

Material examinado: BRASIL. Minas Gerais: Mariana, Parque Estadual do Itacolomi, Estrada do Cibrão, 9-VI-2005, Casarino 46, 47 (OUPR); 9-VI-2005, Jascone 370 (RB).

Material adicional: BRASIL. Minas GeraIs: Mariana, 12-V-1905, Damazio s.n. (RB 36895).

8. Anemia phyllitidis (L.) Sw., Syn. Fil. 155. 1806. $\equiv$ Osmunda phillitidis L., Sp. Pl. 2:1064. 1753.

Figura 2G

Caule reptante, 9-15 mm diâm., com tricomas septados 1-5 mm compr., alaranjados ou castanho claros. Frondes eretas, fasciculadas; pecíolos 13-53 cm compr. (ca. 2/3 do compr. da lâmina), verde amarelado a castanho claro, sulcados adaxialmente, com tricomas semelhantes aos do caule; lâmina pinada, oblongo-ovada a deltóide, membranácea, $11-21 \times 7-16 \mathrm{~cm}$, raque com tricomas semelhantes aos do pecíolo; pinas 3-5 pares, 5,5-8,5 × 1,5-3,5 cm, apical, medianas e basais lanceoladas, ápice agudo ou acuminado, com tricomas curtos ca. $1 \mathrm{~mm}$ compr., esparsos sobre as duas faces das nervuras e margem; nervuras anastomosadas. Esporangióforos eretos, dispostos em duas pinas basais modificadas, excedendo em 2-12 cm a lâmina fértil, peciólulo longo ca. 2 vezes o compr. do esporangióforo.

Esta espécie está amplamente distribuída no Parque Estadual do Itacolomi, ocorrendo em ambientes secos ou úmidos à beira de riachos sombreados ou diretamente expostos ao sol. Possui uma ampla distribuição na região Neotropical, ocorrendo do México a América do Sul e no Brasil de norte a sul, principalmente em florestas úmidas montanas e baixo montanas.

Material examinado: BRASIL. MinAs Gerais: Mariana, Parque Estadual do Itacolomi, Estrada do Cibrão, 24-III-2004, Casarino 25 (OUPR); Ouro Preto, Parque Estadual do Itacolomi, Trilha do Forno, 22-III-2004, Casarino 3 (OUPR); Estrada para Fazenda do Manso, Labiak \& Roschel s.n. 06-VIII-1998 (OUPR 16968); Estrada para Fazenda do Manso, 13-XI-2004, Casarino 31, 35 (OUPR); Trilha do Calais, 23-III-2004, Casarino 11 (OUPR).

\section{Anemia raddiana Link, Hort. Berol. 2. 144. 1833.}

Caule reptante, 2-5 mm diâm., com tricomas septados 2-5 mm compr., castanho alaranjados. Frondes eretas, cespitosas; pecíolos com 16-30 cm compr. (ca. 2/3 do compr. da lâmina); castanho claros, sulcados adaxialmente, com tricomas semelhantes aos do caule; lâmina bipinado-pinatífida, deltóide a oblongo-ovada, cartácea a coriácea, 10-23 × 6-8 cm, raque com tricomas semelhantes aos do pecíolo; pinas 8-13 pares, 3,5-6 $\times$ 1-2 cm, apical e medianas lanceoladas ou oblongolanceoladas, pinatífidas, basais ovadas a oblongoovadas, bipinatífidas, ápice obtuso, com tricomas semelhantes aos da raque nas duas faces; nervuras livres e furcadas. Esporangióforos eretos, delgados, dispostos em duas pinas basais modificadas, excedendo em 4-10 cm a lâmina fértil, peciólulo ca. 1/3 do compr. do esporangióforo.

Esta espécie tem uma ampla distribuição no PEI especialmente nas regiões florestais úmidas. Trata-se de uma espécie endêmica do Brasil com distribuição nos Estados Minas Gerais, Rio de Janeiro, São Paulo, Paraná e Santa Catarina.

Material examinado: BRASIL. Minas Gerais: Ouro Preto, 9-I-1903, Damazio 6 (RB); Parque Estadual do Itacolomi, entre Ouro Preto e passagem para Mariana, 19-I-1994, Roschel s.n. (OUPR 1276); Estrada de Cima, transecto 9, 22-XI-2001, Messias 538 (OUPR); Trilha do Calais, 24-III-2004, Casarino 9, 15(OUPR); Estrada para Fazenda do Manso, 13-IX-2004, Casarino 34 (OUPR); Estrada do Cibrão, 9-VI-2005, Jascone 385 (RB).

10. Anemia tomentosa (Savigny) Sw., Syn. Fil. 157. 1806. $\equiv$ Osmunda tomentosa Savigny, Encycl. 4:652. 1897.

10.1. Anemia tomentosa (Savigny) Sw. var. anthriscifolia (Schrad.) Mickel, Iowa State J. Sci. 36:424. 1962. $\equiv$ Anemia anthriscifolia Schrad., Gott. Gel. Anz. 1824:625. 1824.

Figura 3A

Caule reptante, 8 mm diâm., com tricomas septados 2-8 mm compr., castanhos alaranjados. Frondes eretas, cespitosas, pecíolos com 8-30 cm compr. (ca. 2 vezes compr. da lâmina), castanho escuros, sulcados adaxialmente, com tricomas semelhantes aos do caule na porção proximal, glabrescente na porção distal; lâmina bipinada, deltóide a ovado-deltóide, coriácea, 7-10 × 2,5$3,5 \mathrm{~cm}$, raque com tricomas semelhantes aos do pecíolo; pinas 12-15 pares, $1-2 \times 0,2-0,4 \mathrm{~cm}$, apical lanceolada, medianas e basais lanceoladas ou oblongo-lanceoladas, bipinatífidas, pínulas ovadas a oblongas, ápice obtuso a agudo, com tricomas semelhantes aos da raque nas duas faces; nervuras livres e furcadas. Esporangióforos eretos, delgados, 0,3-0,5 cm, dispostos em duas pinas basais modificadas, excedendo em 1-2 cm a lâmina fértil, peciólulo ca. 1/2 do compr. do esporangióforo. 
Esta variedade cresce em barranco úmido sombreado por afloramentos rochosos na Estrada do Cibrão, próximo a uma população de A. oblongifolia. Segundo Mickel (1962) esta é a variedade mais comum de A. tomentosa, e pode ser distinguida das outras pela lâmina deltóide, pecíolo de coloração escura, lobos das pínulas agudos, esporangióforos mais longos que a lâmina. Possui ampla distribuição na América do Sul e no Brasil ocorre do Estado do Amazonas ao Rio Grande do Sul.

Material examinado: BRASIL. Minas Gerais: Mariana, Parque Estadual do Itacolomi, Estrada do Cibrão, 24-III-2004, Casarino 23 (OUPR); Ouro Preto, Serra do Itacolomi, 27-I-1977, Carauta 2281 (RB).

\section{Anemia villosa Willd., Sp. Pl. 5:92. 1810.} Figuras 3B, C

Caule ereto, 7-13 mm diâm., com tricomas septados 1-4 mm compr., castanho alaranjados. Frondes eretas, fasciculadas; pecíolos da fronde estéril 7-18 cm compr., pecíolos da fronde fértil 14-33 cm compr. (ca. 2 vezes ou do mesmo compr. da lâmina), castanhos a castanho amarelados, sulcados adaxialmente, com tricomas semelhantes aos do caule; lâmina pinado-pinatífida, oblonga a oblongo-lanceolada, membranácea a cartácea, 8,5-32 × 3,2-9,0 cm, raque com tricomas semelhantes aos do pecíolo; pinas apical, medianas e basais, pinatífidas, oblongas a oblongo-lanceoladas, 11-20 pares, 1,6-4,5 × 0,7-1,8 cm, ápice obtuso, tricomas $1-2 \mathrm{~mm}$ compr., semelhantes aos da raque nas duas faces; nervuras livres e furcadas. Esporangióforos eretos, delgados, 0,5-0,9 cm larg., dispostos em duas pinas basais modificadas, excedendo em 1-18 cm a lâmina fértil, peciólulo curto ca. 1/3 do compr. do esporangióforo.

Esta espécie está amplamente distribuída no PEI, ocorrendo em barrancos úmidos sombreados, perto de riachos ou em locais expostos ao sol e secos. Geralmente A. villosa é confundida com A. raddiana e A. imbricata, mas pode ser diferenciada pelo indumento, forma e consistência da lâmina e esporangióforos. A. imbricata possui o indumento castanho escuro a nigrescente, esporangióforos robustos (com mais de $1 \mathrm{~cm}$ larg.) e lâmina deltóide a oblongo-ovada. A. raddiana diferenciase pela lâmina bipinado-pinatífida, deltóide a oblongoovada, cartácea a coriácea. Possui ampla distribuição na América do Sul e ocorre de norte ao sul do Brasil, de Roraima a Santa Catarina.

Material examinado: BRASIL. MinAs Gerais: Ouro Preto, Parque Estadual do Itacolomi, Trilha do Pico do Itacolomi, 18-X-2004, Casarino 36 (OUPR); Trilha do
Forno, 22-III-2004, Casarino 2, 4, 5 (OUPR); Trilha do Calais, 23-III-2004, Casarino 21, 30 (OUPR); Estrada para Fazenda do Manso, 13-IX-2004, Casarino 33 (OUPR); Estrada para Bacia do Custódio, 22-XI-2004, Casarino 37, 38, 39 (OUPR); Trilha do Cibrão, 9-VI-2005, Jascone 400 (RB).

\section{LYGODIACEAE M. Roem.}

Caule reptante, com tricomas; frondes escandentes, com crescimento contínuo; pecíolos cilíndricos; lâminas bipinadas, pinas palmadas ou pinadas, raque volúvel, nervuras livres ou anastomosadas; esporangióforos dispostos na margem modificada dos segmentos, esporos tetraédrico-globosos, triletes.

Esta família é formada pelo gênero Lygodium que possui distribuição pantropical e cerca de 25 espécies. Na área do PEI foi encontrada somente uma espécie na região remanescente de floresta estacional semidecidual.

12. Lygodium volubile Sw., J. Bot. (Schrader) 1801(2): 304. 1803.

Figura 3D

Planta escandente, caule reptante, subterrâneo. Raque com crescimento contínuo, volúvel, glabrescente, lâminas bipinadas, membranácea, 13-18 × 10-16 cm; pina-raque castanha, tricomas ca $0,8 \mathrm{~mm}$ compr., amarelados; pínulas 4-6 pares, 5-9 × 1,0-1,8 cm larg., lanceoladas, margens serreadas; nervuras livres efurcadas. Esporangióforos dispostos na margem modificada do segmento das pínulas férteis com prolongamento de nervuras, um por segmento.

Esta espécie foi encontrada na borda de mata, na Estrada do Cibrão. Foram observados indivíduos jovens crescendo no interior da mata. Está amplamente distribuída da América Central a América do Sul. No Brasil ocorre do Estado do Pará ao Rio Grande do Sul.

Material examinado: BRASIL. Minas Gerais: Mariana, Parque Estadual do Itacolomi, Estrada do Cibrão, 24-III-2004, Casarino 24, 29, 32 (OUPR).

\section{SCHIZAEACEAE Kaulf.}

Plantas terrestres. Caule ereto, com tricomas; frondes eretas, fasciculadas ou cespitosas, monomorfas ou dimorfas; pecíolos sulcados adaxialmente, com tricomas ou glabros; lâmina simples ou dicotomizada; nervuras livres, furcadas; esporangióforos pinados ou pinatífidos, na margem distal da lâmina, esporos monoletes. 


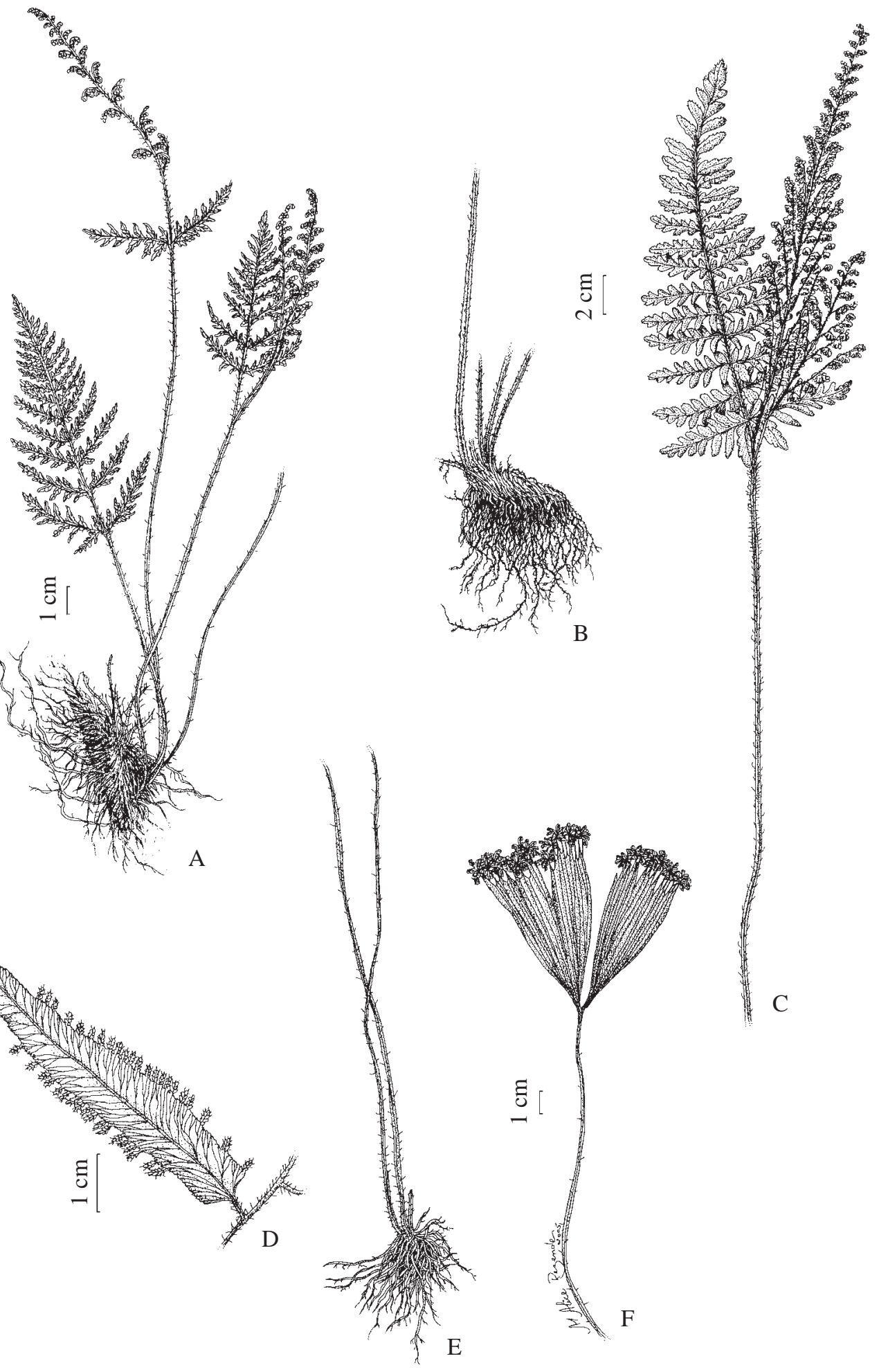

Figura 3. A. Anemia tomentosa var. anthriscifolia, hábito (Casarino 23). B-C. Anemia villosa. B. Caule (Jascone 400). C. Fronde (Casarino 15). D. Lygodium volubile, pínula (Casarino 29). E-F. Schizaea elegans. E. Caule (OUPR 7329). F. Fronde fértil (OUPR 7346).

Figure 3. A. Anemia tomentosa var. anthriscifolia, habit (Casarino 23). B-C. Anemia villosa. B. Stem (Jascone 400). C. Frond (Casarino 15). D. Lygodium volubile, pinnula (Casarino 29). E-F. Schizaea elegans. E. Stem (OUPR 7329). F. Fertile frond (OUPR 7346). 
Atualmente a família Schizaeaceae está constituída por dois gêneros Actinostachys e Schizaea, totalizando cerca de 30 espécies, com distribuição pantropical (Smith et al. 2006). No PEI está representada por somente uma espécie.

13. Schizaea elegans (Vahl) Sw., J. Bot. (Schrader) 1800(2):103. 1801. 三Acrostichum elegans Vahl, Symb. Bot. 2:104, t. 50. 1791.

Figuras 3E, F

Caule ereto 3-7 mm de diâm., tricomas ca. 1-2,5 mm compr., castanho escuros. Frondes eretas, fasciculadas; pecíolo 5,5-29,5 cm compr. (ca. 3/4 do compr. da fronde), castanho, sulcado adaxialmente, tricomas na porção proximal, glabrescente na porção distal; lâmina flabelada, dicotomizada, cartácea, 5,58,5 × 4,5-6,5 cm, glabra nas duas faces; nervuras livres e furcadas. Esporangióforos pinados, dispostos ao longo da margem distal da lâmina.

Esta espécie ocorre nos remanescentes de floresta. Distribui-se do Sul do México até a América do Sul. No Brasil é encontrada do Amazonas a Santa Catarina.

Material examinado: BRASIL. MinAs Gerais: Mariana, Parque Estadual do Itacolomi, Estrada do Cibrão, 8-VIII-1998, Labiak s.n. (OUPR 7346); VIII-1998, Silva s.n. (OUPR 7329).

Conclusão - Em levantamento prévio feito nos herbários foram encontradas seis espécies de Schizaeales com ocorrência no Parque Estadual do Itacolomi (Anemia elegans, A. mandioccana, A. oblongifolia, A. imbricata, A. ferruginea var ahenobarba e Schizaea elegans). Neste estudo foram inventariados 14 táxons dos gêneros Anemia, Lygodium e Schizaea, aumentando em mais de 100\% o número de espécies conhecidas para o Parque.

Verificou-se que duas espécies não têm registros recentes no Parque Estadual do Itacolomi. Embora Anemia elegans tenha sido coletada recentemente em campo rupestre na Serra do Capanema, localidade próxima da área de estudo, o último registro no Parque Estadual do Itacolomi data de 1903. A outra espécie, A. mandioccana, só possui um registro em 1902 em uma das áreas mais úmidas do Itacolomi, apesar de geralmente formar densas populações nas florestas úmidas da Costa Atlântica brasileira. Acredita-se que as queimadas ocorridas no Parque possam ter contribuído para a perda ou alteração do hábitat dessas espécies.

Anemia lanuginosa Bong. ex Sturm e A. hirsuta (L.) Sw., embora ocorram no município de Ouro Preto, foram excluídas deste trabalho por não terem sido registradas na área de estudo.

Foi observada durante as coletas nos meses secos (junho a agosto), uma diminuição das populações de Anemia. Algumas espécies encontravam-se secas e estéreis, sendo difícil a sua identificação. Apenas Lygodium volubile e Anemia phyllitidis, que ocorrem no interior da mata em ambientes úmidos e sombreados, não mostraram populações alteradas neste período.

Dos táxons estudados, seis são considerados endêmicos do Brasil (Anemia ferruginea var. ahenobarba, A. imbricata, A. mandioccana, A. nervosa, A. pallida e A. raddiana).

Embora não se possa precisar o número de espécies que no passado compunham a flora de Schizaeales do Parque Estadual do Itacolomi, este estudo traz uma importante contribuição sobre a composição da flora de Schizaeales com a descrição de características diagnósticas, distribuição geográfica e chaves de identificação, sendo mais um instrumento para o conhecimento da biota e conseqüentemente preservação desta Unidade de Conservação.

Agradecimentos - Ao Técnico em Herbário e amigo Jorge Luis da Silva por todo apoio no trabalho de campo e ensinamentos. Ao Prof. Carlos Eduardo Jascone e Dr. Alexandre Salino pela ajuda na identificação das espécies. Ao Dr. John Mickel pelas sugestões. A ilustradora Maria Alice Rezende. Aos curadores dos herbários visitados. À da Universidade Federal de Ouro Preto, pelo auxílio concedido.

\section{Referências bibliográficas}

DUTRA, V.F., MESSIAS, M.C.T.B. \& GARCIA, F.C.P. 2005. Papilionoideae (Leguminosae) nos campos ferruginosos do Parque Estadual do Itacolomi, Minas Gerais, Brasil: florística e fenologia. Revista Brasileira de Botânica 28:493-504.

HASEBE,M.,OMORI,T.,NAKAZAWA,M.,SANO,T.,KATO, M. \& IWATSUKI, K. 1994. $r b c L$ gene sequences provide evidence for the evolutionary lineages of leptosporangiate ferns. Procceding of the National Academy of the United States of America 91:5730-5734.

KRAMER, K.U. 1990. Schizaeaceae. In The families and genera of vascular plants (K. Kubitzki, ed.). v.1. Pteridophytes and Gymnosperms (K.U. Kramer \& P.S. Green, eds.). Springer Verlag, New York. p.258-263.

MAGUIRE, B., RICHARD, B., COWAN, S. \&WURDACK, J. J. 1969. The botany of the Guayana Highland - part VIII. Memoirs of the New York Botanical Garden 18:1-290.

MICKEL, J.T. 1962. A monographic study of fern genus Anemia, subgenus Coptophyllum. Iowa State College Journal of Science 36:349-492. 
MICKEL, J.T. 1982. The genus Anemia (Schizaeaceae) in Mexico. Brittonia 34:388-413.

MICKEL, J.T. \& BEITEL, J.M. 1988. Pteridophyte flora of Oaxaca, Mexico. Memoirs of the New York Botanical Garden. 46:1-568.

MICKEL, J.T. \& SMITH, A. 2004. The pteridophytes of Mexico. Memoirs of the New York Botanical Garden. 88:1-1055.

PICHI-SERMOLLI, R.E.G. 1996. Authors of scientific names in Pteridophyta. Royal Botanic Gardens, Kew.

REED, C.L. 1947. The phylogeny and ontogeny of the Pteropsida. I. Schizaeales. Boletim da Sociedade Broteriana. 21:71-197.

SEHNEM, A. 1974. Esquizeáceas. Flora Ilustrada Catarinense. Herbário Barbosa Rodrigues, Santa Catarina, Itajaí.

SMITH, A.R. 1995. Schizaeaceae. In Flora of the Venezuelan Guayana v.2. Pteridophytes, Spermatophytes, Acanthaceae, Araceae. (P.E. Berry, B.K. Holst \& K. Yatskievych, eds.) Timber Press, Portland, Oregon, p.288-296.
SMITH, A.R., PRYER, K.M., SCHUETTPELZ, E., KORALL, P., SCHNEIDER, H. \& WOLF, P.G. 2006. A classification for extant ferns. Taxon 55:705-731.

SMITH, A.R., PRYER, K.M., SCHUETTPELZ, E., KORALL, P., SCHNEIDER, H. \& WOLF, P.G. 2008. Fern classification. In Biology and evolution of fern and Lycophytes (T.A. Ranker and C.H. Haufler, eds.). Cambridge University Press, Cambridge, p.417-467.

TRYON, R.M \& TRYON, A.F. 1982. Fern and allied plants, with special reference to Tropical America. Springer Verlag. New York.

VELOSO, H.P., RANGEL FILHO, A.L.R. \& LIMA, J.C.A. 1991. Classificação da vegetação brasileira adaptada a um sistema universal. IBGE, Rio de Janeiro.

WERNECK, M.S., PEDRALLI, G., KOENIG, R. \& GISEKE, L.F. 1999. Florística e estrutura de três trechos de uma Floresta semidecídua na Estação Ecológica do Tripuí, Ouro Preto, MG. Revista Brasileira de Botânica 23: 97-106. 